\title{
ANALYSIS OF METHANE DIFFUSION FLAMES
}

\author{
Swati Bhardwaj ${ }^{1}$, Pramod Bhatia ${ }^{2}$, Sushant Ahuja ${ }^{3}$ \\ ${ }^{1}$ Itm University, Sec 23 A Gurgaon, India \\ ${ }^{2}$ Itm University, Sec 23 A Gurgaon, India \\ ${ }^{3}$ Itm University, Sec 23 A Gurgaon, India
}

\begin{abstract}
Steady-state global chemistry calculations for 09 different flames in earth gravity were made using an axisymmetric CFD code. Inverse diffusion flames of methane in earth gravity with varying oxidizer compositions $(21,30,40,50,60,70,80,90,100 \% 02$ mole fraction in N2) stabilized on a $5.5 \mathrm{~mm}$ diameter burner. The effect of oxygen enrichment and gravity variations on flame shape and size of inverse diffusion flames have been reported in the paper. The salient feature in the combustion phenomenon of methane fuel is that the flame length is invariably increases with flame velocity and adiabatic flame temperature.
\end{abstract}

Keywords: Diffusion flames, Axisymmetric, Methane, CFD, Oxygen enhancement

\section{INTRODUCTION}

Laminar Diffusion Flames are those flames in which oxidizer combines with fuel by diffusion.. The fuel comes from the jet, while the oxidizer is air; the fuel and oxidizer mix before being introduced (by diffusion) into the flame zone. Sunderland et.al.[1] experimentally investigated effects of variation of oxygen enhancement and gravity on normal and inverse laminar jet diffusion flames. Ethanefueled laminar gas-jet diffusion flames were observed, emphasizing the effects of oxygen enhancement (up to $100 \% \mathrm{O}_{2}$ ). Zhang Yi et.al.[2] have reported the experimental studies of inverse flames in earth gravity using burner inside diameter $0.75,1.53,3.02,4.56$ and $10.1 \mathrm{~mm}$. Oxygen mole fractions in nitrogen were $0.21,0.3,0.4$, and 1 . Fuels were methane, ethylene and propane. Yoshimoto T. et al.[3] 2005 were analysed flame stability limits and found that flame stability limits are highly dependent on the flow configurations and species of the fuel. Saini [4] experimentally investigated heat flux distributions, total radiativeheat loss and the spectral radiation intensities for oxygen enhanced normal and inverse laminar ethane diffusion flames (the oxygen mole fraction in the oxidizer was varied as $21 \%, 30 \%, 50 \%$ and $100 \%$ in $\mathrm{N}_{2}$ ). Bhatia[5] computationally investigated normal and inverse jet Diffusion flames under oxygen enrichment and gravity variation. He found that Oxygen enhanced conditions resulted in increased flame temperatures and Inverse diffusion flames were more sooting and can emit harmful gases at high oxygen concentrations.

\section{COMPUTATIONAL TOOL USED TO STUDY}

\section{FLAME BEHAVIOR OF METHANE FLAMES}

A time-accurate CFDC (Computational Fluid Dynamics with Chemistry) code (Katta et al.) known as UNICORN (UNsteady Ignition and COmbustion with ReactioNs) is used to predict flame behaviour of Methane flames under varying oxygen concentration. UNICORN is a timedependent, axisymmetric mathematical model that solves for axial- and radial-momentum equations, continuity, and enthalpy- and species-conservation equations to simulate a variety of dynamic jet flames.

The governing equations, written in the cylindricalcoordinate system, are as follows:

$$
\frac{\partial(\rho)}{\partial t}+\frac{1}{r} \frac{\partial(r \rho u)}{\partial r}+\frac{\partial(\rho v)}{\partial z}=0
$$

\section{COMPUTATIONAL TOOL USED TO STUDY}

\section{FLAME BEHAVIOR OF METHANE FLAMES}

A time-accurate CFDC (Computational Fluid Dynamics with Chemistry) code (Katta et al.) known as UNICORN (UNsteady Ignition and COmbustion with ReactioNs) is used to predict flame behaviour of Methane flames under varying oxygen concentration. UNICORN is a timedependent, axisymmetric mathematical model that solves for axial- and radial-momentum equations, continuity, and enthalpy- and species-conservation equations to simulate a variety of dynamic jet flames.

\section{GRID AND DOMAIN DESCRIPTION}

The present simulations involved a round $5.5 \mathrm{~mm}$ diameter burner and quiescent ambient gas at 0.98 bar and $298 \mathrm{~K}$. Figure 1 presents the geometry of the axisymmetric computational domain. The computational domain extends $100 \mathrm{~mm}$ and $50 \mathrm{~mm}$ in the axial (z) and radial (r) directions, respectively, and is represented by a staggered, clustered $201 \times 101$ grid system. The co-flow velocity is set at $1 / 10$ th of the jet velocity. The effect of the round $5.5 \mathrm{~mm}$ diameter burner on flow dynamics is modeled by including an adiabatic rectangular body of thickness $0.45 \mathrm{~mm}$ inside the computational domain. The body height is $10 \mathrm{~mm}$. 


\section{GLOBAL CHEMISTRY}

Five species that are involved in the global chemistry calculations are: Hydrocarbon $\left(\mathrm{CH}_{4}\right)$, Oxygen $\left(\mathrm{O}_{2}\right)$, Nitrogen $\left(\mathrm{N}_{2}\right)$ or Argon (Ar), $\mathrm{H}_{2} \mathrm{O}$ and Carbon-dioxide $\left(\mathrm{CO}_{2}\right)$. Radiation heat losses are not included in this model. . It is a one step reaction modeled as follows:

$$
\mathrm{CH}_{4}+2 \mathrm{O}_{2}+\mathrm{N}_{2}=\mathrm{CO}_{2}+2 \mathrm{H}_{2} \mathrm{O}+\mathrm{N}_{2}
$$

\section{RESULTS AND DISCUSSION}

Earth-gravity (1-g) Inverse Diffusion Flames (the oxygen mole fraction in the oxidizer was varied as $21 \%, 30 \%, 40 \%$, $50 \%, 60 \%, 70 \%, 80 \%, 90 \%$ and $100 \%$ in $\mathrm{N}_{2}$ ). Effect of oxygen enhancement on temperature profile in figures given below.

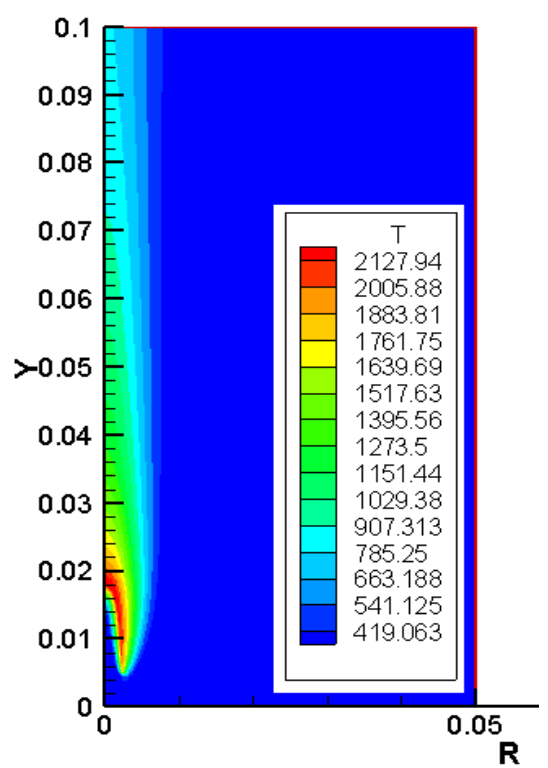

Fig.1 Shape of Inverse Flames with 21\% Oxygen

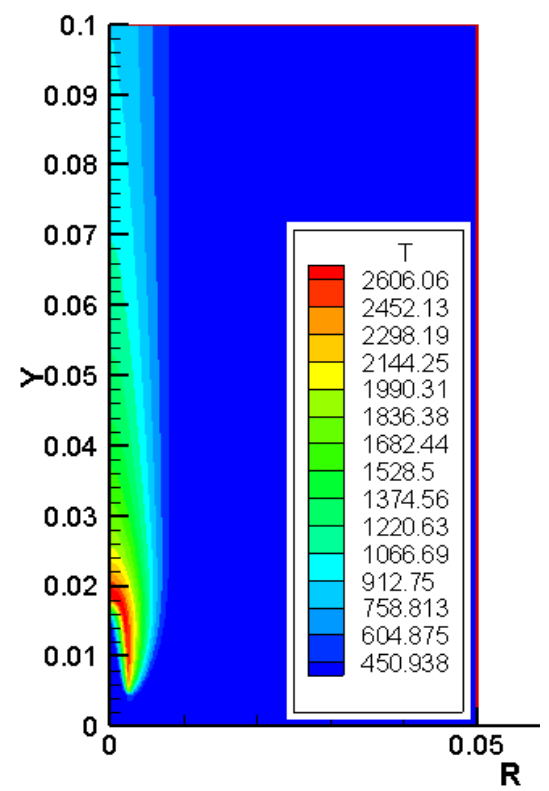

Fig. 2 Shape of Inverse Flames with 30\% Oxygen

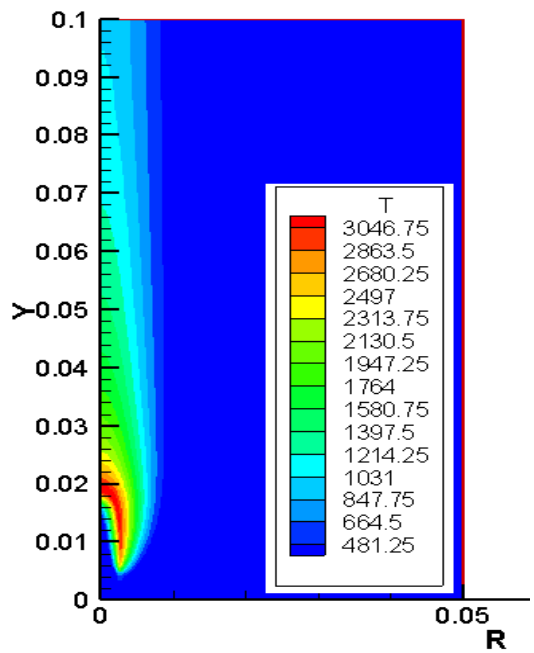

Fig. 3 Shape of Inverse Flames with 40\% Oxygen

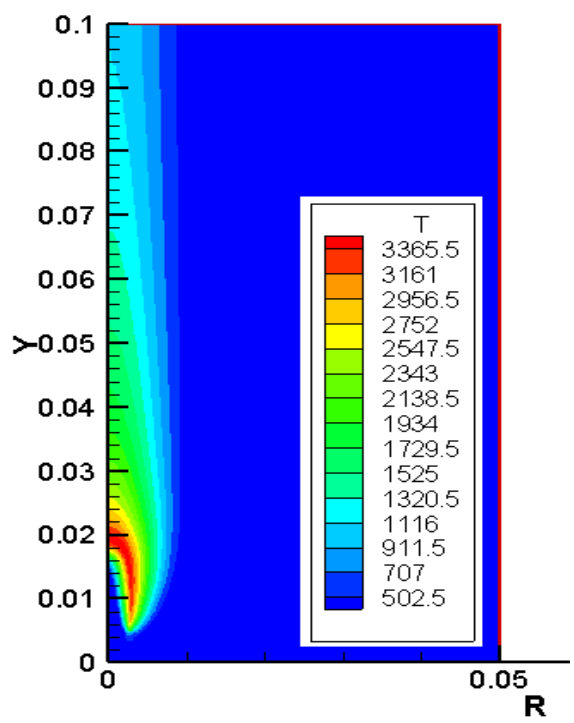

Fig.4 Shape of Inverse Flames with 50\% Oxygen

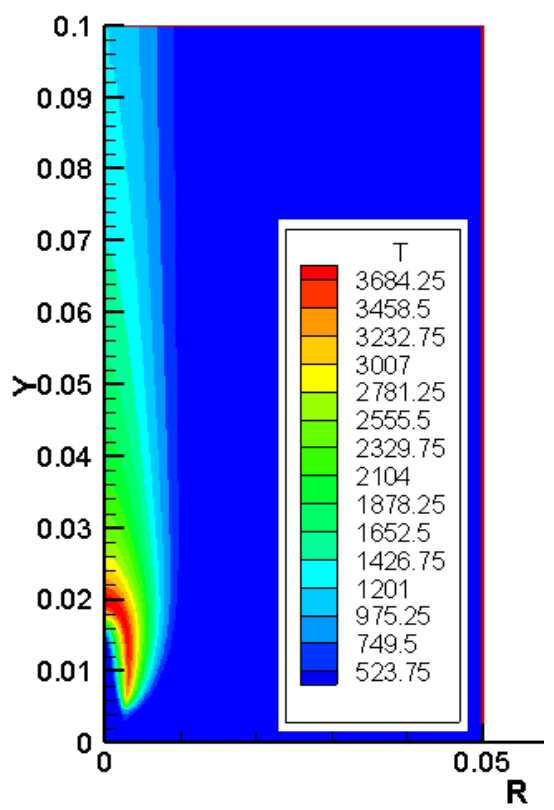

Fig.5 Shape of Inverse Flames with 60\% Oxygen 


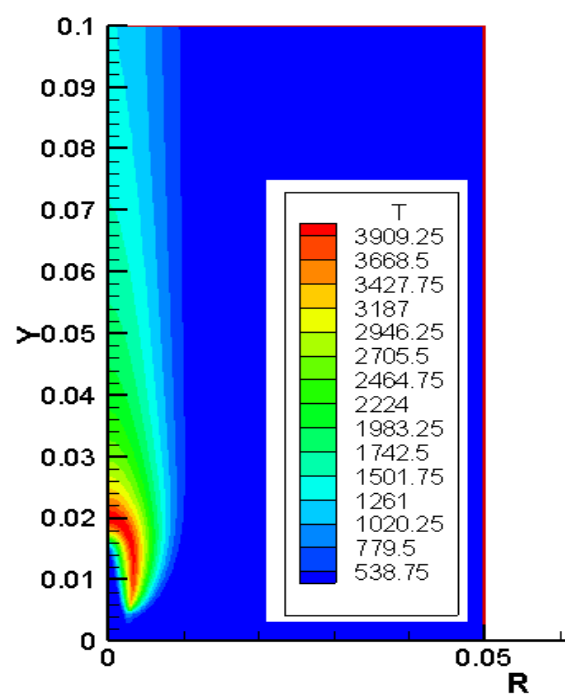

Fig.6 Shape of Inverse Flames with 70\% Oxygen

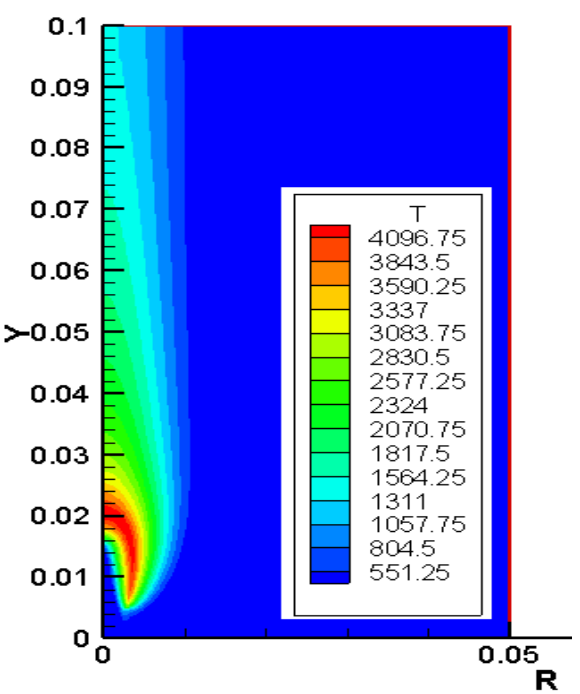

Fig.7 Shape of Inverse Flames with $80 \%$ Oxygen

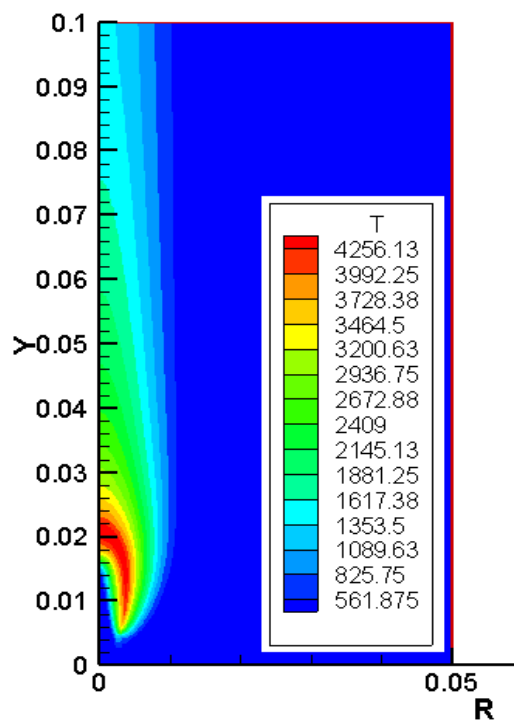

Fig.8 Shape of Inverse Flames with 90\% Oxygen

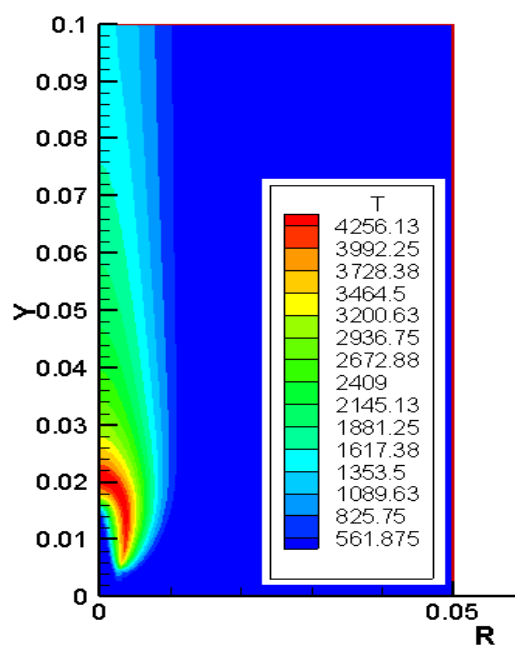

Fig.9 Shape of Inverse Flames with $100 \%$ Oxygen

\begin{tabular}{|c|c|c|c|c|c|}
\hline Cases & $\begin{array}{c}\text { O }_{2} \mathbf{M} \\
\text { OLE } \\
\text { FRAC } \\
\text { TION }\end{array}$ & $\begin{array}{c}V_{\text {jet }} \\
(\mathrm{mm} / \mathrm{s})\end{array}$ & $\begin{array}{c}\mathbf{L f} \\
(\mathrm{mm})\end{array}$ & $\begin{array}{c}\text { Wf } \\
(\mathbf{m m} \\
)\end{array}$ & $\begin{array}{c}\text { Max. } \\
\operatorname{Temp}(K)\end{array}$ \\
\hline $\begin{array}{c}\boldsymbol{C A S E} \mathbf{I} \\
{\left[1 \mathrm{~g} \_ \text {ID }\right.} \\
\text { F21] }\end{array}$ & $21 \%$ & 866 & 12 & 4.8 & 2127.94 \\
\hline $\begin{array}{c}C A S E 2 \\
{\left[1 \mathrm{~g} \_I D\right.} \\
\text { F30] }\end{array}$ & $30 \%$ & 866 & 12.2 & 5.0 & 2606.06 \\
\hline $\begin{array}{c}\boldsymbol{C A S E} 3 \\
{\left[1 \mathrm{~g} \_ \text {ID }\right.} \\
\text { F40] }\end{array}$ & $40 \%$ & 866 & 12.4 & 5.15 & 3046.75 \\
\hline $\begin{array}{c}C A S E 4 \\
{\left[1 g_{-} \text {ID }\right.} \\
\text { F50] }\end{array}$ & $50 \%$ & 866 & 12.5 & 5.2 & 3365.5 \\
\hline $\begin{array}{c}\boldsymbol{C A S E} 5 \\
\text { [1g_ID } \\
\text { F60] }\end{array}$ & $60 \%$ & 866 & 12.9 & 5.7 & 3684.25 \\
\hline $\begin{array}{c}C A S E 6 \\
{\left[1 g_{-} \text {ID }\right.} \\
\text { F70] }\end{array}$ & $70 \%$ & 866 & 13.1 & 5.8 & 3909.25 \\
\hline $\begin{array}{c}\boldsymbol{C A S E} 7 \\
{\left[1 \mathrm{~g} \_ \text {ID }\right.} \\
\text { F80] }\end{array}$ & $80 \%$ & 866 & 13.45 & 6.0 & 4096.25 \\
\hline $\begin{array}{c}C A S E \boldsymbol{E} \\
{\left[1 \mathrm{~g} \_ \text {ID }\right.} \\
\text { F90] }\end{array}$ & $90 \%$ & 866 & 13.98 & 6.1 & 4256.13 \\
\hline $\begin{array}{c}C A S E 9 \\
{\left[1 g_{-} \text {ID }\right.} \\
\text { F100] }\end{array}$ & 100 & 866 & 14.5 & 6.1 & 4256.13 \\
\hline
\end{tabular}

\section{CONCLUSIONS}

Global chemistry were performed for methane fueled jet diffusion flames emphasizing the effect of oxygen enhancement and major findings are the oxygen enhancement resulted in increased flame temperatures. For inverse diffusion flames, oxygen enhancement caused an increase in $\mathrm{CO}$ and soot emission. Flame-length increases when going from air to pure oxygen environment. For 
inverse diffusion flames, radiation emission increased with oxygen enhancement.

\section{REFERENCES}

[1]. Sunderland, P.B., Mendelson, B.J., Yuan, Z. G., Urban, D.L., "Shapes of Buoyant and Nonbuoyant Laminar Jet Diffusion Flames," Combustion and Flame, Vol. 116(1999),p. 376-386.

[2]. Zhang Yi , "Measurement of Inverse Diffusion Quenching Limits", Spring Technical Meetng of Combustion Institute, (2012)

[3]. Yoshimoto T., "Stability Limits and Behavior of Inverse Diffusion Flames", Asia Pacific Conference on combustion, Adelaide, Australia( 2005).

[4]. Saini, M.K., Spectral and Total Radiation Properties of Oxygen Enhanced Normal and Inverse Laminar Diffusion Fl ames, MS Thesis, School of Mechanical Engineering Department, Purdue University( 2006).

[5]. BhatiaP., Normal and Inverse Laminar Jet-Diffusion Flames under Oxygen Enhancement and Gravity-Variation, Ph.D. Thesis, Department of Mechanical Engineering, Purdue University ( 2008).

[6]. Baukal, C.E., Oxygen-Enhanced Combustion, CRC Press(1998).

[7]. V.V. Toro, A.V. Mokhov, H.B. Levinsky, M.D. Smooke "Combined experimental and computational study of laminar, axisymmetric hydrogen- air diffusion flames", Proceedings of the Combustion Institute,

[8]. A.V. Mokhov et al., Experimental and computational study of $\mathrm{C}_{2} \mathrm{H}_{2}$ and $\mathrm{CO}$ in a laminar axisymmetric methaneair diffusion flame Proceedings of the Combustion Institute Vol.31 (2004), p. 485-492.

[9]. V.R. Katta , W.M. Roquemore, "Numerical studies on the structure of two- dimensional $\mathrm{H}_{2} /$ air premixed jet flame",Combustion and Flame(1995), p. 21-40.

[10]. Information on http://engr.iupui.edu /departments/ me/research /_documents_gradprojects/abshire_msme.pdf, Indiana University Purdue University Indianapolis. 